\title{
Turbulence and Energy Conversion Research
}

R. A. Hutchinson

July 1985

Prepared for the U.S. Department of Energy under Contract DE-AC06-76RLO 1830

Pacific Northwest Laboratory Operated for the U.S. Department of Energy by Battelle Memorial Institute 


\title{
DISCLAIMER
}

This report was prepared as an account of work sponsored by an agency of the United States Government. Neither the United States Government nor any agency thereof, nor any of their employees, makes any warranty, express or implied, or assumes any legal liability or responsibility for the accuracy, completeness, or usefulness of any information, apparatus, product, or process disclosed, or represents that its use would not infringe privately owned rights. Reference herein to any specific commercial product, process, or service by trade name, trademark, manufacturer, or otherwise, does not necessarily constitute or imply its endorsement, recommendation, or favoring by the United States Government or any agency thereof. The views and opinions of authors expressed herein do not necessarily state or reflect those of the United States Government or any agency thereof.

\author{
PACIFIC NORTHWEST LABORATORY \\ operated by \\ BATTELLE \\ for the \\ UNITED STATES DEPARTMENT OF ENERGY \\ under Contract DE-AC06-76RLO 1830
}

\begin{tabular}{|c|c|}
\hline \multicolumn{2}{|c|}{ Printed in the United States of America } \\
\hline$\hat{A} \hat{A}$ & tence \\
\hline $\begin{array}{l}\text { National Tecl } \\
\text { United States }\end{array}$ & tion Service \\
\hline United States & f Commerce \\
\hline 5285 & ad \\
\hline Spring & 22161 \\
\hline & \\
\hline & \\
\hline & \\
\hline & Price \\
\hline Pages & \\
\hline 001-025 & A02 \\
\hline 026-050 & $A 03$ \\
\hline 051-075 & A04 \\
\hline 076-100 & A05 \\
\hline $101-125$ & A06 \\
\hline $126-150$ & $A 07$ \\
\hline $151-175$ & $A 06$ \\
\hline $176-200$ & A09 \\
\hline $201-225$ & A010 \\
\hline 226-250 & A011 \\
\hline $251-275$ & A012 \\
\hline $276-300$ & $A 013$ \\
\hline
\end{tabular}


TURBULENCE AND ENERGY

CONVERSION RESEARCH

\author{
R. A. Hutchinson
}

July 1985

Prepared for

Energy Conversion and Utilization Technologies Division

Office of Energy Systems Research Conservation and Renewable Energy U.S. Department of Energy under Contract DE-ACO6-76RLO-1830

Pacific Northwest Laboratory

Richland, Washington 9935? 
• 
PREFACE

This study was completed for the Division of Energy Conversion and Utilization Technologies (ECUT) in the Department of Energy. The division's mission is to identify and research long-range technology concepts for more efficient energy use. To meet its goals, the ECUT staff established a planning and systems analysis project that was responsible for conducting this study.

This report is one of a series of studies in support of the ECUT research planning effort. This volume examines the role of fluid mechanics research (particularly turbulence research) in improving energy conversion systems. It emphasizes fluid mechanical system design as a major barrier and discusses the details of two important areas: fluidization and cavitation. Other documents in the series contain assessments of energy conservation technology areas, appraisat of research projects for support, and data reference sources. PubTications from this project include the following:

Abarcar, R., and D. R. Johnson. 1984. ECUT Data Reference Series: Lightweight Materials for Ground Transportation. PNL-5192, Pacific Northwest Laboratory, Richland, Washington.

Abarcar, R., and D. R. Johnson. 1984. ECUT Data Reference Series: HighTemperature Materials for Advanced Heat Engines. PNL-5193, Pacific Northwest Laboratory, Richland, Washington.

Bomelburg, H. J. 1983. Efficiency Evaluation of 0xygen Enrichment in Energy Conversion Processes. PNL-4917, Pacific Northwest Laboratory, Richtand, Washington.

Chockie, A. D., and D. R. Johnson. 1984. ECUT Data Reference Series: Boilers. PNL-5195, Pacific Northwest Laboratory, Richland, Washington.

Hane, G. J. 1983. Efficiency Evaluation of the DISC, DHC, and DI Diesel Engines. PNL-4568, Pacific Northwest Laboratory, Richland, Washington.

Hane, G. U., et a1. 1983. A Preliminary Overview of Innovative Industrial Materials Processes. PNL-4505, Pacific Northwest Laboratory, Richland, Washington.

Hane, G. J., et al. 1984. A Review of Studies of Research Dpportunities in Energy Conservation. PNL-4571, Pacific Northwest Lahoratory, Richland, Washington. 
Hane, G. J. and D. R. Johnson. 1984. ECUT nata Reference Series: Otto Cycle Engines in Transportation. PNL -5191 , Pacific Northwest Laboratory, Richland, Washington.

Hopp, W., et al. 1981. An Overview of Energy Conservation Research Opportunities--Executive Sumary. PNL-3944, Pacific Northwest Laboratory, Richland, Washington.

Hopp, W., et al. 1981. An Overview of Energy Conservation Research Doportunities. PNL-3944, Pacific Northwest Laboratory, Richland, washington.

Hopp, W., et al. 1982. Identification of Energy Conservation Research Opportunities: A Review and Synthesis of the Literature. PNL-3966, Pacific Northwest Laboratory, RichTand, Washington.

Hutchinson, R. A. 1985. Applications of Laser Diagnostics in Energy Conservation Research. PNL-5281, Pacific Northwest Lahoratory, Richland, Washington.

Hutchinson, R. A. and H. J. Bomelburg. 1984. Capabilities of Laser Diagnostics for Combustion and Flowfields. PNL-5280, Pacific Northwest Laboratory, Richland, Washington.

U.S. Department of Energy. 1981. The 1981 ECUT Work Element Appraisal. DOE/CE-0024, U.S. Department of Energy, Washington, D.C.

U.S. Department of Energy. 1983. Energy Conversion and Utilization Technologies Program Report, 1981-1982. T.S. Department of Energy, Washington, D.C.

Vallario, R. W., and D. E. DeBellis. 1984. State of Technology of Direct Contact Heat Exchanging. PNL-50ne, Pacific Northwest Laboratory, Richland, Washington.

Vitullo, M., C. Winter, and D. R. Johnson. 1984. The Executive Information System. PNL-5190, Pacific Northwest Laboratory, Richland, Washington.

Young, J. K., E. A. Griffin, and J. A. Russell. 1984. Opportunities for Energy Conservation Through Biotechnology. PNL-5295, Pacific Northwest Laboratory, Richland, Washington.

Young, J. K. and D. R. Johnson. 1984. ECIJT Data Reference Series: Ammonia Synthesis Energy Use and Capital Stock Information. PNL-5194, Pacific Northwest Laboratory, Richland, washington. 


\section{ACKNOWLEDGMENTS}

The author extends his appreciation to Dave Brenchley and Bill Cliff, for their thoughtful contributions to this report, and to Marvin Gunn for his support and patience. 


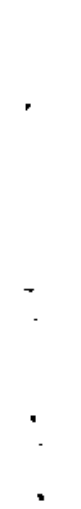

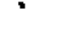




\section{CONTENTS}

PREFACE $\ldots \ldots \ldots \ldots \ldots \ldots \ldots \ldots \ldots \ldots \ldots \ldots \ldots \ldots \ldots \ldots \ldots \ldots \ldots \ldots \ldots \ldots \ldots \ldots \ldots \ldots . \ldots \ldots$

ACKNOWLEDGMENTS $\ldots \ldots \ldots \ldots \ldots \ldots \ldots \ldots \ldots \ldots \ldots \ldots \ldots \ldots \ldots \ldots \ldots \ldots$

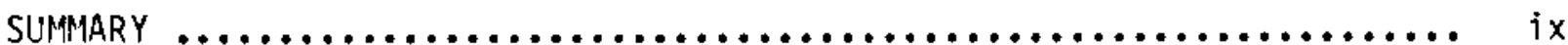

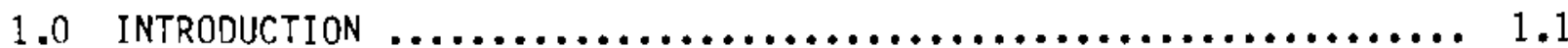

2.0 ENERGY CONSERVATION, FLUIDS ENGINEERING AND
FLUIDS RESEARCH $\ldots \ldots \ldots \ldots \ldots \ldots \ldots \ldots \ldots \ldots \ldots \ldots \ldots \ldots \ldots \ldots \ldots \ldots \ldots \ldots \ldots$

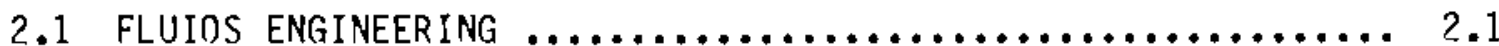

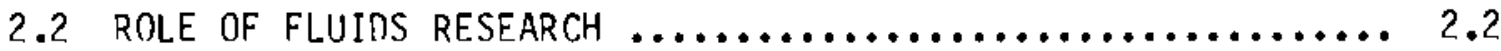

3.0 Flutd RESEARCh AND TURBUlence $\ldots \ldots \ldots \ldots \ldots \ldots \ldots \ldots \ldots \ldots \ldots \ldots \ldots$

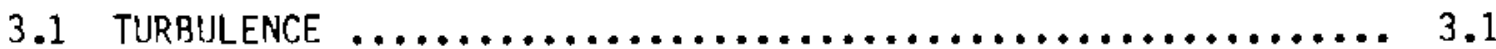

3.2 TURBULENCE IN CONVERSION SYSTEMS $\ldots \ldots \ldots \ldots \ldots \ldots \ldots \ldots \ldots \ldots \ldots . . \ldots \ldots$

3.3 SAMPLE RESEARCH TOPICS $\ldots \ldots \ldots \ldots \ldots \ldots \ldots \ldots \ldots \ldots \ldots \ldots \ldots \ldots \ldots$

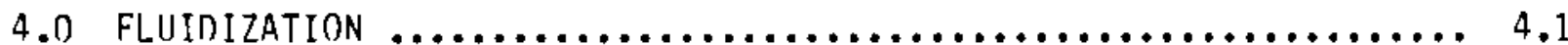

4.1 FLUIOIZATION APPLICATIONS $\ldots \ldots \ldots \ldots \ldots \ldots \ldots \ldots \ldots \ldots \ldots \ldots \ldots . \ldots \ldots$

4.2 Significance of FLUIDIZATION $\ldots \ldots \ldots \ldots \ldots \ldots \ldots \ldots \ldots \ldots \ldots \ldots \ldots$

4.3 TURBIJENCE IN FLUIDIZATION $\ldots \ldots \ldots \ldots \ldots \ldots \ldots \ldots \ldots \ldots \ldots \ldots \ldots . \ldots$

4.3 .1 In-Bed Turbulence $\ldots \ldots \ldots \ldots \ldots \ldots \ldots \ldots \ldots \ldots \ldots \ldots \ldots . \ldots \ldots$

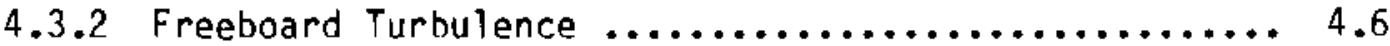

4.4 FLUIDIZATION RESEARCH $\ldots \ldots \ldots \ldots \ldots \ldots \ldots \ldots \ldots \ldots \ldots \ldots \ldots \ldots \ldots$

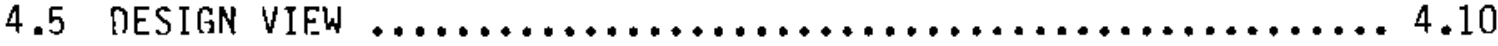

4.6 CONCLUSIONS FOR ECUT .......................... 4.11

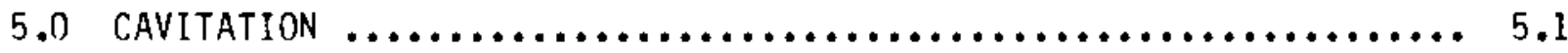

5.1 DEVICES IN WHICH CAVITATION OCCURS $\ldots \ldots \ldots \ldots \ldots \ldots \ldots \ldots \ldots \ldots$

5.2 SIGNIFICANCE OF CAVITATION $\ldots \ldots \ldots \ldots \ldots \ldots \ldots \ldots \ldots \ldots \ldots \ldots \ldots \ldots \ldots \ldots \ldots$ 


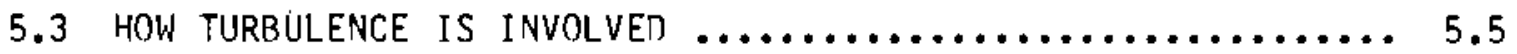

5.3 .1 Viscous Effects $\ldots \ldots \ldots \ldots \ldots \ldots \ldots \ldots \ldots \ldots \ldots \ldots \ldots \ldots . \ldots . \ldots$

5.3 .2 Surface Roughness $\ldots \ldots \ldots \ldots \ldots \ldots \ldots \ldots \ldots \ldots \ldots \ldots \ldots . \ldots . \ldots$

5.3.3. Turbutent Shear Flows $\ldots \ldots \ldots \ldots \ldots \ldots \ldots \ldots \ldots \ldots \ldots \ldots . \ldots . \ldots$

5.3 .4 Dissolved Gas Effects $\ldots \ldots \ldots \ldots \ldots \ldots \ldots \ldots \ldots \ldots \ldots \ldots . . \ldots$

5.4 RESEARCH $\ldots \ldots \ldots \ldots \ldots \ldots \ldots \ldots \ldots \ldots \ldots \ldots \ldots \ldots \ldots \ldots \ldots \ldots \ldots \ldots \ldots$

5.5 DESIGN VIEW $\ldots \ldots \ldots \ldots \ldots \ldots \ldots \ldots \ldots \ldots \ldots \ldots \ldots \ldots \ldots \ldots \ldots \ldots . . \ldots . \ldots$

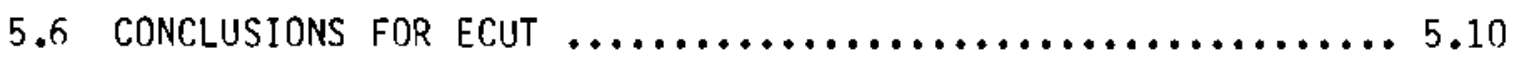

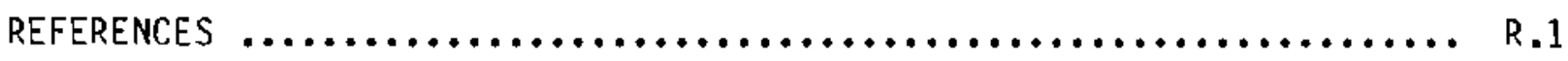


SUMMARY

This report examines the role of fluid mechanics research (particularly turbulence research) in improving energy conversion systems. The complexity of both fluid mechanics research and its application to energy conversion systems makes it difficult to obtain research results that provide useful information for system designers. Fluid mechanics research is often incapable of providing this information because fundamental understanding in this area is currently incomplete. Innovative approaches that "design around" a problem are often more effective.

This study was sponsored by the Energy Conversion and Ittilization Technologies (ECUT) Division of the U.S. Department of Energy (DOE). The ECUT Program performs applied research and exploratory development to create a technology hase for designing more energy-efficient energy conversion and utilization devices. ECUT's interest in turbulence and fluid mechanics is based on the results of previous ECUT-sponsored research, which indicated the significance of turbulence/combustion interactions in engines and turbulence/heat transfer effects around boiler tubes.

Turbulent flow, the most prevalent flow regime in engineering systems, involves random, unpredictable macroscopic motions, in contrast to stable, readily analyzed laminar flow. Turbulence is perhaps the fundamental problem in fluid mechanics. For this reason, and because of the prevalence of turbulence, fluid mechanics lacks a foundation of thoroughly analyzed cases upon which to base most practical designs. Design difficulties are present in almost all applications, not just the special cases. Therefore, despite substantial qualitative fluid mechanics knowledge and many well-established quantitative results, the design of fluid mechanical devices must of ten be based more on experience than analysis.

Problems that are intrinsic to fluid mechanical design of systems are one source of difficulty. Fluids mechanics research generally does not address these system design problems directly, although they may be caused specifically by a lack of engineering knowledge. This type of design problem should be addressed by performing more applied research. More specific or more difficult 
design problems should be addressed hy encouraging innovative design approaches: improving system configurations or developing alternative designs may obviate the need for research. However, solutions to many problems will require a great deal of fundamental effort and considerable improvements in understanding. Applied research and innovative designs must be sought to achieve energy conservation goals, even as fundamental questions remain unanswered.

This report primarily addresses potential applied research activities. Such activities attempt to avoid areas of overwhelming difficulty, as well as areas in which research may soon be unnecessary due to innovations. Practically, the report's focus on turbulence restricts research possibilities to very difficult problems which in general makes applied research prospects fairly dim. To better focus the problems, basic processes can be identified (such as particle transport and heat transfer) to which turbulence makes an integral contribution. Using these processes to systematically examine the operation of energy conversion systems, such as gas turbines and engines, provides a list of turbulence applications from which research problems and projects might be developed. These topics require individual examination to determine their merit.

In this report two of the listed application areas are selected as examples: fluidization and cavitation. Research needs in generat, and research possibilities for ECUT in particular, are examined. Roth areas involve highly difficult, multiphase flow situations in which complete simuTation or calculation may not be possible. Yet both areas appear to have possibilities for applied work. Fluidization involves the suspension of a seething bed of particles in a flow of liquid or gas. Because of its superb heat transfer and mixing capabilities, fluidization has become a truly generic technology, with applications in heat exchangers, particles handling, and mixing and chemical reactors (including combustors). The other selected application area, cavitation, involves the formation of a bubble in a liquid that occurs when the local static pressure drops below the vapor pressure. When such hubbles collapse in pumps, valves, and turbines or on propellers, the resulting shocks can cause damage ranging from mild to catastrophic. 
Fluidized bed systems are very complex to implement because of the many demands they make on the state of the art in solids handling and fluid mechanics. Turbulence in these systems has not heen carefully investigated, despite twenty years of technical development, partly because of the many other topics vying for fluidization researchers' time. Although a great many reseach possibilities exist, too little is known about them to decide if the work will be generic in application. Currently, it is probably best to simply monitor basic research results, with the exception of fluidized bed heat exchangers, which are generic in themselves. Results from heat exchanger work might also be used by researchers concerned with reacting fluidized beds. Industry and recovery and environmental protection programs also have a significant interest in this area, so transferring technical developments should not be too difficult. This work should have significant energy impact because of the tremendous range of possible applications.

Cavitation problems involve highly difficult design and operational factors. The goal of cavitation research, however, is to understand the phenomenon well enough to prevent it. In this, cavitation research is rather like tribology, which attempts to prevent wear. Cavitation impacts are similarly difficult to assess. Relatively recent cavitation research has shown that cavitation inception is very closely involved with turbulence, because turbulence causes local pressure fluctuations. Unfortunately, almost no correlations have been found between turbulence measurements and cavitation incidence; thus more basic research is necessary. In the meantime, it is recommended that ECUT evaluate cavitation in a manner similar to the ECUT tribology work. The pumps and valves in which cavitation occurs are critical to energy conversion and industrial process systems. Unfortunately, many of these systems are plagued by design problems that cavitation research cannot solve; sometimes cavitation is caused by standard design procedures. Thus, ECUT's current role in this area should involve a system-level assessment rather than active cavitation research. 


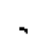

: 


\subsection{INTRODUCTION}

Turbulent flow is defined as chaotic and unpredictable flow characterized by the random, macroscopic mixing of the fluid. Analysis of such flows is perhaps the last major problem of Newtonian mechanics. As an intellectual challenge, as well as a practical problem of great importance, turbulence has attracted some of the best minds in the fields of mathematics, physics, and engineering. Although turbulence is probably the central problem in fluid mechanics research, it has proved difficult to address on a more practical level. The contribution of turbulence to a process can be good or bad--indeed it is often both at the same time. For example, turbulence in a heat exchanger certainly increases heat transfer; unfortunately, it can also increase pressure drop, and may cause debilitating vibrations as well. It is important to realize that turbulence is almost always present in energy processes, and has significant impact on performance. This report addresses applied fluid mechanics research and emphasizes generic turbulence work because such work may help provide solutions to important energy conversion problems.

This report primarily focuses on engineering fluid mechanics, which deals with the theoretical activity of design rather than the scientific investigation of events. Advances in energy systems rely on the further development of engineering fluid mechanics, especially physical insights and modeling approaches applicable to the myriad flow situations that confront an energy system designer. Applied research into turbulent processes must be part of practical engineering problem solving, where a reasonable answer now is vastly more valuable than a perfect answer at some undetermined point in the future. Sometimes research will not be the best approach to an engineering roadblock-. often reassessing system-level concerns or developing an innovative design approach can provide more concrete gains.

Pacific Northwest Laboratory (PNL) has contracted with the 11.S. Department of Energy (DOE) to assess applied fluid mechanics research in the specific area of turbulent phenomena in energy conversion systems. The work was sponsored by the Energy Conversion and Utilization Technologies (ECUT) Division, which performs applied research and exploratory development of innovative design 
approaches to develop the technology base for energy conservation. This technology hase includes computer models and advanced measurement techniques as well as new approaches for energy conversion and utilization. The ECIJT Program's approach is to create useful design tools and computer models dealing with processes of fundamental, generic importance.

The ECUT Program has a special interest in the role of turbulence in such processes because of the work the program has sponsored in internal combustion engines. Laser measurements applied to such engines are leading to an understanding of the detailed mechanisms of certain forms of turbulent combustion (Witze and Dyer 1984). Turbulence and in-cylinder fluid mechanics appear to have a far more important role in combustion (and thus in engine efficiency) than has been previously believed. The understanding developed by experimental work is being utilized in computer models useful in the design of production engines.

Other turbulent processes in energy conversion systems may also be suitable for applied research by the ECUT Program. However, the relationship between energy conservation, fluid mechanical hesign, and fluids research must be carefully considered when planning such work. Fluids engineering must be the primary consideration, rather than filling gaps in scientific knowledge; these issues are discussed in Chapter 2. In Chapter 3 the design-oriented methodology described in Chapter 2 is used to develop a list of applied fluid mechanics research topics. Two cases were selected from this list for their initial promise and the variety of insights they could provide into the problem of selecting applied research areas. The selected cases--fluidization and cavitation--are presented in Chapters 4 and 5, including a summary discussion of ECUT's potential role in each area. 


\subsection{ENERGY CONSERVATION, FLUIDS ENGINEERING, AND FLUIDS RESEARCH}

Certain types of fluid mechanics research can help attain energy conservation goals. In some cases it is fairly easy to describe the connection between fluid mechanical causes and energy consumption effects, hut this is not true for many of the most difficult and important prohlems. For example, the flow over and around a car determines its aerodynamic drag, and the details of how this directly affects the car's fuel consumption are well known. In contrast, while flows within the cylinders of the car's engine are known to affect its ability to burn gasoline, it is not possible, at the moment, to completely explain how. Work on cylinder design may improve fuel consumption, but there are few specific cause-and-effect rules to follow. This chapter examines such connections in a general sense to evaluate what role fluid mechanics research on some of the more difficult energy conversion-related problems can play in fulfilling energy conservation ohjectives.

\subsection{FLUIDS ENGINEERING}

Fluid mechanics knowledge is applied to systems design through fluids engineering, which serves as the intermediary between research and energy conservation goals. Fluids engineering also causes much of the difficulty in implementing more effective fluid mechanical systems. Engineering (as opposed to engineering science) deals with the theoretical activity of design, rather than the scientific investigation of events. "Science," in this context, means identifying a particular phenomenon and following its progress to its outcome, which is usually unique.

The design process, on the other hand, works in the opposite direction. The designer must hegin with a desired outcome, or at least a set of variables to be optimized according to various criteria, and must then devise configurations to provide that outcome. Thus, he has no cause-and-effect relationships to guide him directly to a solution; indeed a unique solution is not guaranteed (Shercliff 1981). If the system is somehow under-specified, he will have many 
answers. If it is over-specified, ill-posed, or ill-conditioned (a), he will have none at all. Though such a situation seems nonintuitive, it actually involves working backward hoping to specify a condition that never existed and has no particular natural reason for existence.

An engineering system, therefore, cannot be designed by simply developing a more rigorous scientific knowledge of the type of phenomena that appear to be involved in that system. There is still a considerable probability in some situations that the designer "can't get there from here." However, within the realm of energy conversion system design, scientific knowledge is very important. This is because the system sets the framework within which many basic (though perhaps poorly understood) physical and chemical processes may occur.

One of the most important of these processes is fluid mechanics. Fluids might be viewed as carrying the inputs from the system framework (i.e., flow boundaries, inlets and outlets) down to the microscopic level at which most of the other basic processes (e.g., chemistry, heat transfer) operate. Flow details are increasingly viewed as being critical to system performance. To return to the example of the automobile: for both the aerodynamics and the incylinder flows, localized effects such as flow over window recesses or through the inlet and exit valves must be understood and modified in order to significantly improve performance. Thus research, as well as design, can be necessary. It is important to note, however, that research with no subsequent design has no energy impact-although it may eventually serve as the basis for other research. This is why ECUT must emphasize design in its research planning.

\subsection{ROLE OF FLUIDS RESEARCH}

There are still many fundamental unknowns about fluid mechanics that require research. Unfortunately, these difficulties are central to most practical fluid mechanical systems--they include boundary layers and turbulence. There is no particularly well-understood area within the field to provide

(a) These are mathematical terms that relate to whether a problem has one solution, many solutions, or none. 
designers with the information they need while leaving the "fringes" to researchers interested in special cases. Currently, most fluid mechanical designs are developed in part by iteration and empiricism--simply improving current efforts bit by bit. It is axiomatic that a new, untried design never performs as well as expected.

It may be possible, in certain circumstances, to mitigate the effects of limited knowledge through superior design, or, as it is more commonly known, innovation. This is a somewhat vague concept, so an extended example of a new class of innovative designs will be given. The example evolves from the need to change certain attributes of a new design without major remanufacturing. Ideally, the design could change itself. It could then adapt to transients and changes in operating conditions without being forced to run in a suboptimal state. Such designs are now possible with the aid of sensitive transducers and microcomputer-based control software, and (potentially) intelligent software. Such systems would be much easier to implement today, with microcomputers, than they would have been only ten years ago. These systems might he viewed as mimicking biological systems such as the cardiovascular system, which is selfadaptive through the use of a huge number of feedback mechanisms.

There are both crude and sophisticated examples of this type of device on drawing hoards or in use in fluid-mechanical applications today. One observer (Shercliff 1981) gives as examples certain ocean wave energy devices that adjust to the type of waves they experience, the use of gust alleviation on aircraft, and the use of anti-sound to cancel sound. A very recent example is a small turbopower unit for an automobile that eliminates overheating problems at part throttle by sensing when to change its internal configuration (Dunne 1984). Even more impressive are aerospace systems such as the guidance systems on launch vehicles and the gimballed engines on the space shuttle. In the energy industry, the nuclear sector has developed very sophisticated power plant hydraulics that operate as self-adapting systems. Finaliy, the microcomputer control systems in automobiles provide self-adaption to a certain extent for automobile engines. 
Developing such systems will certainly be a challenge for designers, not least because it will require familiarity with yet another discipline--electronics. But these systems provide a far greater ability to optimize designs, since the systems can fine-tune themselves. Certainly such an approach might require extra knowledge, and thus research--but this need not always be so. Research is sometimes a necessary condition for improved fluid mechanical systems; it is never sufficient, as a design must always be executed.

Aspects of the relationships between research and knowledge and design have been emphasized here because they are critical to understanding applied fluid mechanics research needs. This is hest illustrated by the fact that every day fluid mechanical systems are designed that include flows that cannot be described accurately--particularly the turbulent or multiphase flows so prevalent in energy conversion systems. Fluid mechanics research cannot be counted upon to provide answers whenever they are needed. Sometimes only basic, long-term research is worthwhile. Sometimes other approaches might be effective: invention, improved systems analysis, or a better control mechanism (perhaps self-adaptive). There are areas that are suitable for applied work, but they must be appropriately targeted. ECUT, in particular, does a specially selected type of applied research/exploratory development, which requires very careful analysis and planning. 


\subsection{FLUIDS RESEARCH ANO TURBULENCE}

The previous chapter described the relationship between fluids research and energy conservation, and emphasized the role of fluid mechanical design. In this chapter particular aspects of fluids research are discussed. Because of its findings in combustion work, the ECUT Program is interested in other areas where turbulence is critical to the performance of energy conversion systems. ECUT's combustion work involves attempting to develop knowledge useful to designers in a substantially unknown area previously subject only to basic research. This would also be the case with many other turbulence-affected phenomena. This chapter discusses turbulence, narrows down applied research possibilities, and presents the rationale for selecting the two case areas examined in Chapters 4 and 5.

\subsection{TURBIULENCE}

Turbulence can be described as fluid motion involving random macroscopic mixing, with a wide range of scales in the size and time duration of the motions involved. This range is possible because of the three-dimensional, vortical nature of turbulence. The onset of turbulence is basically governed by geometry and the Reynolds number, which is the ratio of inertial to viscous forces in the flow. Flows with high Reynolds numbers are considered turbulent.

Turbulent energy is gained at boundaries, or at interface layers between fluids with different momenta, where vortices form. This energy is then lost through viscosity as large vortices break up into smaller and smaller motions that eventually dissipate. The boundary layer, which receives a large share of attention in engineering fluid mechanics, is a simplification based on the well-validated assumption that the important region of the fluid is the thin layer next to a surface. This assumption is especially important when analyzing heat transfer and flow friction. Free shear flows, another major turbulent

flow of practical interest, occur in regions far from the wall. Reacting flows are often free shear flows.

The engineering field currently deals with turbulence in terms of correlations and averages on one level or another, and a great deal of work has been 
done on these over the years. Although the statistics have become quite complex, there is concern among turbulence researchers (Lumley 1983) that even stochastic aspects of flows are not always adequately expressed by current averaging and modeling schemes. Different processes have different time scales that cannot be combined by simple methods such as averaging, and the range of these scales (small to large) increases rapidly with Reynolds number. Such lumping of frequency-dependent data from experiments allows little accuracy or resolution in models using the data, yet it is difficult to avoid because of the immense complexity of detailed approaches. Various modeling approaches are used to bridge the gap between the inaccuracy of leaving out some scales completely and the impossibility of including all the scales for any but lowReynolds number flows.

Underlying these complex statistics is the presence of deterministic aspects known as coherent structures in the governing dynamics of turbulent flow (Laufer 1983). The last twenty years of turbulence research have led to a growing realization that the transport properties of most turbulent shear flows are dominated by non-random large-scale vortex motions (Cantwell 1981). Turbulence research now emphasizes direct analysis or measurement of complex unsteady flowfields under rather restricted conditions. This approach is elaborate but apparently successful because of advances in instrumentation and computer equipment. It also includes renewed emphasis on flow visualization for identifying new flow structures and as a conceptual aid in tying analytical descriptions of complex processes to simple pictures. Such methods of identification are crucial as the organized motions heing studied vary in form, strength, and scale between one flow and the next. Despite these experimental advances, knowledge of this structure has not been incorporated into practical engineering methods. Through the models that are used to narrow the range of flow scales, connections with theory are just heginning to be developed.

Despite the fact that progress toward a rigorous analytic theory of turbulent flows has been very slow, a surprisingly good qualitative understanding of turbulence and its effects has been accumulated (Rogallo and Moin 1984). 
Certain fundamental results are sufficiently well established to serve both as test cases for more complex approaches and as encouragement to do more applied and fundamental work.

\subsection{TURBULENCE IN CONVERSION SYSTEMS}

Turbulent flows are actually more common than orderly and predictable laminar flows. The impact of turbulence on energy conversion is suggested by Table 3.1, which gives examples of important conversion devices and components in which turbulent flows occur. Estimates of populations and present fuel consumptions are provided for some of these devices. In some of the devices, however, turbulence may not be an important issue. Even fewer of the devices are likely to require applied research (assuming there is no way to design around the problem). However, research can still be important when attempting to optimize a system, which is required for increased efficiency and energy conservation.

TABLE 3.1. Examples and Importance of Sample Thermal Energy Conversion Devices and Components $(a)$

\begin{tabular}{|c|c|c|}
\hline Device & Population & $\begin{array}{c}\text { Energy (order of magnitude) } \\
\text { Throughput (10 } 15 \text { Btu) }\end{array}$ \\
\hline Pump & -- & .5 \\
\hline Compressor & -- & 2 \\
\hline Furnace & -- & 20 \\
\hline Boiler & $2 \times 106$ & 10 \\
\hline Steam Turbine & -- & 10 \\
\hline Gas Turbine & -- & 5 \\
\hline Gasoline Engine & $160 \times 106$ & 15 \\
\hline Diesel Engine & - & 2 \\
\hline
\end{tabular}

(a) Sources include Hane and Johnson (1984), Abarcar, Hane, and Johnson (1984), Imhoff, Liberman, and Ashton (19B2), and Rodine and Vitullo (1980). 
Table 3.2a gives examples of fundamental processes in which turbulence makes an integral contribution. If these processes are the basis of either an engineering problem or a possible solution, then research aimed at improving the knowledge base for design should be considered. Much of this work will be basic in nature. But in important cases, such as the turbulence/combustion interactions in the engine cylinder studied by ECUT, applied research should be considered. Each element in the matrix can be considered in developing a sample listing of research areas; Table $3.2 b$ gives a partial listing originating from Table 3.2a. Topics marked with an asterisk have already attracted ECUT interest. Some research has been completed on almost all of the topics, but may involve only relatively recent undertakings.

These areas are not optimal research projects; they are better viewed as starting points when developing project ideas. Each topic must be examined carefully to determine its proper focus, although often too little information is available to make informed judgements. For example, turbulent heat transfer in gas turbines is a suggested research topic. Gas turbines are characterized by intense turbulence and high-speed flows. The turbulence in the first few gas turbine blade rows is probably considerable. Based on admittedly sparse experimental results, the heat transfer appears to increase significantly at such high turbulence levels (Bradshaw and Simonich 1978, Blair 1983). If the high turbulence does promote high heat transfer, this information could be critical to designers attempting to push turbine-operating temperatures higher.

These experimental results could be valuable for other applications. Extremely high turbulence can also exist in piston engines, even with very little mean flow. Such information is important for engine design because of the apparent relationships between turbulence and flame speed and between flame speed and temperature. Very high turbulence is also present in certain types of furnaces. Thus there is a good basis for generic work on high-turbulence heat transfer if the turbulence in the experiment can be shown to be similar to that in the applications. Current work on this topic by R. J. Moffatt at Stanford however, takes an application-specific approach because the nature of the turbulence involved in the various cases is so poorly understood. 
TABLE 3.2a. Turbulence-Related Effects - Examples and 0ccurrences in Practice

Components and Devices

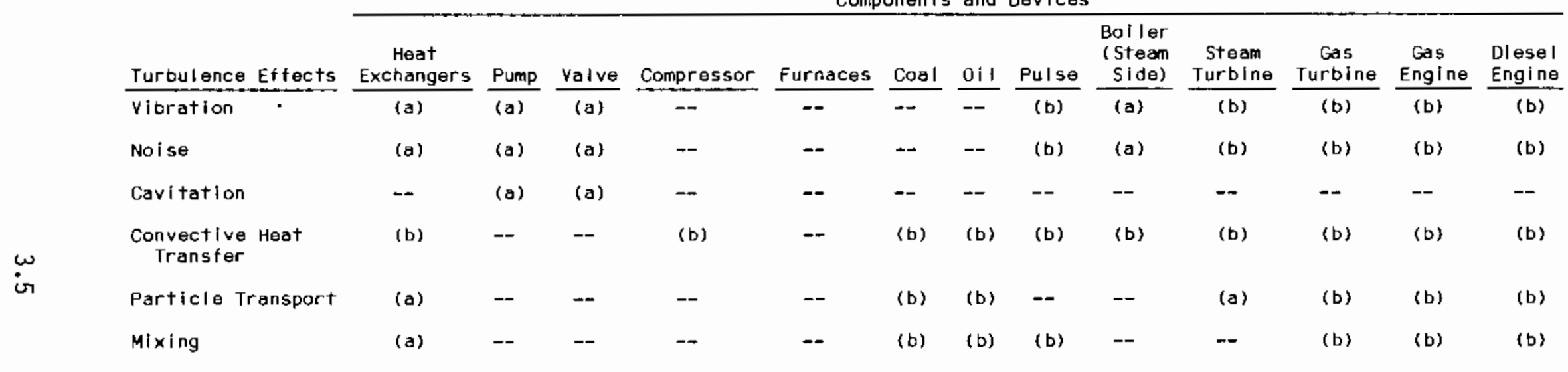

(a) May occur.

(b) Generally occurs. 
TABLE 3.2b. Sample List of Fluid Mechanics Research Areas

Heat exchanger vibrations (a)

Heat transfer enhancement flow control in heat exchangers (a)

Multi-phase heat exchangers (e.g. fluidized-bed) fouling in heat exchangers $(a)$

Causes for vibration and noise in pumps, valves

Cavitation in pumps, valves

Heat transfer in compressors (a)

Particle dispersion in furnaces

Elutriation in fluidized beds

Mixing in oil furnaces

Noise in pulse combustors(a)

Heat transfer enhancement for boiler tubes (a)

Droplet transport in low pressure steam turbines

Heat transfer in supercritical turbines

Turbulence and turbine blade vibrations

Particle transport in gas turbines

Turbulence/chemistry interactions in gas turbine combustors

Turbulent heat transfer in gas turbines

Mixing methods in otto cycle engines (a)

Fuel sprays in diesels (a)

Heat transfer to engine cylinder walls(a)

Exhaust manifold/system tuning

Knock a)

(a) Areas in which ECIJT has sponsored research.

\subsection{SAMPLE RESEARCH TOPICS}

Recause of the complexity of many of the cases in Table 3.2b, and the fact that the 1 ist is far from complete, two research topics--fluidization and cavitation--were selected for further analysis. Both topics involve multiphase flows. Multi-phase flows are an immense practical challenge for fluid mechanicians because they are present in so many applications.

The two topics were also chosen because they appear to offer opportunities for measurements using advanced techniques, particularly the laser-based techniques previously studied under the ECUT program (Hutchinson and Romelburg 1984, Hutchinson 1985). The topics both involve applications that are already in common use, and thus improvements are clearly a conservation task. Although 
previous work has been conducted in these areas, there are additional possibilities for the ECUT program that hear examination. Both of these topics are strongly tied to fundamental research. In addition, cavitation has important system-level design concerns to be examined, and fluidization has an incredible array of applications to be investigated. Thus each area contributes a different type of insight to the program planning analysis ECUT must perform to conduct fluid mechanics research. 



\subsection{FLUIDIZATION}

Fluidization involves the suspension of particles in a flow of liquid or gas. Although some authorities (Zabrodsky 1966) note that bubhles can serve as the particles in a fluidized bed for a gas-liquid system, this chapter deals primarily with the classic gas-solid fluidized hed systems, or gas fluidized beds. These beds are used in an increasing number of process applications, from particle sintering and heat exchangers to reactors and combustors. Although improved conversion efficiencies often result when fluidized beds are used, their implementation is often based initially on their ability to convert difficult batch materials handling and conversion tasks to smooth, continuous flow operations. There is great potential for improved controllability from fluidized bed operations, but improved designs and control methods are difficult to develop because too little is known about bed mechanics and the role of random, turbulent motions. The complexities of fluidization and the possible needs for applied research are discussed in this chapter. Applications of fluidization and its resulting significance are reviewed. Then the current knowledge of the role of turbulence in fluidization and prospects for research are presented. Finally, the design perspective and the conclusions for ECUT are discussed.

From a process engineering standpoint, fluidized beds have a number of desirahle properties. When brought to a fluidized state by hlowing gas or liquid through them granular materials possess the property of fluidity, i.e., the fluid/particle mixture will flow and there is a high degree of mixture uniformity. This excellent mixing of solids and the effective transport between the fluid and solid phases are the qualities that first brought fluidized beds into use in petroleum refining (Yurushalmi and Squires 1977). Temperatures are basically uniform throughout a bed, and any newly introduced solid or fluid is very rapidly brought to bed temperature. In addition, the capabilities of the bed as a heat transfer medium are exceptional, as heat transfer to wall and immersed surfaces is extremely high.

There are several regimes of fluidization, which apparently depend on such flow characteristics as velocity and distribution and such particle attributes 
as size and shape. Most of the published data involve fine solids, although coarse solid applications are very important. Regimes relevant to most applications can be described as follows (Yurushalmi, et al. 1978): as the flow of gas through the bed of particles is increased, the hed first expands, then forms bubbles. Next, the bed moves to a turbulent condition (as opposed to the localized turbulence in the bubbling bed), in which bubbles are no longer identifiable and bed density fluctuations become very significant, with gas velocity several times greater than particle terminal velocity. At yet higher flow speeds, there is a mode called the fast-fluidized bed, which is of considerable interest for several applications, including combustion. It is important to remember that the incidence of each of these modes is dependent on both particle and gas flow parameters, and that they each have practical applications. Trends, if any, are toward using beds of higher velocity or higher pressure when increased reaction rates are needed.

\subsection{FLUIDIZATION APPLICATIONS}

Fluidization has been applied to a large number of solids handiing and processing tasks for a variety of reasons. For instance, fluidized beds are an effective approach to increasing the rate of heat transfer between walls and process streams. In other cases the properties of fluidized beds permit conversion of batch processes to continuous operation. Automation (and perhaps in the future precise computer control) is also facilitated by carrying out a process in a fluidized bed (Zabrodsky 1966). Finally, the ability of tbese beds to uniformly mix and effectively handle heterogeneous solids has proved to be very important.

In the past two decades, fluidization technology and fluidized-bed reactor operations have been applied to a wide variety of industries. The technology has been used in the chemical and petroleum industries, in the coal combustion and conversion industry, in metal extraction and processing, in environmental and drying applications, and in other fields requiring techniques for handling solids. These applications have been derived mostly from research and development on comnercial and semicommercial fluidized beds. Perhaps the best known and most important applications from an energy conversion standpoint are the 
fluidized-bed catalytic crackers of the petroleum refining industry and the fluidized-bed combustors of the coal and solid fuels conversion industry. But there are hundreds of other applications, including innovative ones not yet fully realized, that are very significant as well.

Some of these innovations involve further development of the various modes of fluidization. The fluidized beds of the future will not all be based on the standard bubbling bed developed by the chemical industry several decades ago. Some will depend on fast fluidization, a technique in which (as noted earlier) fine particulates and high gas velocities are used to form an entrained, turbulent, dense suspension that is in some respect similar to the freeboard of a bubbling bed. The most popular applications for fast fluidization are in combustion, fluid-bed catalytic cracking, and coal gasification. Other innovations involve operating a bed at high pressure, a technique that has received the most attention in combustion applications because of its enhanced heat transfer and possibilities for combined cycle power generation.

\subsection{SIGNIFICANCE OF FLUIDIZATION}

Fluidization technology is being adopted in an increasing number of process applications. It has proved to be very effective in both energy conversion and process applications, in some cases permitting conversion to continuous operation from batch processing or allowing tighter control of the product stream. In addition, fluidization technology has a key role in a number of new processes, such as powder metallurgy and combined cycle power generation. Thus the benefits of fluidization range from increased efficiency through increased product yields and quantity to the production of new and valuable products.

Of primary interest here, however, is the role of fluidization in energy conversion applications. The clearest examples of the influence of fluidization technology on the current energy scene are in fluidized-bed boilers and in petroleum refinery reactors. Since 1980, fluidized-bed boilers (FBB) have captured a rapidly increasing percentage of the coal-fired boiler market, growing from five percent in 1980 to 20 percent in 1981 (Schroppe and Gamble 1982). Industrial boilers consumed over 50 million short tons of coal in 1980 , or about 1.3 quads of energy. Although the technology still needs refinement, 
the more attractive features of FBB compared with conventional units have persuaded many buyers. These advantages include reduced $\mathrm{NO}_{x}$ emissions with no need for flue gas scrubbers, dry, solid, and easily handled waste; multifuel capability with little ash agglomeration or slagging and no need for extensive fuel preparation; and reduced size due to increased heat transfer efficiency (Siman-Tov and Jones 1980).

Fluidized beds are used in almost every petroleum refinery as reactors in the second largest energy-consuming industrial process in the United States. For example, roughly .44 quads of energy (based on 1980 U.S. oil consumption) are used in fluidized-bed catalytic crackers, of which .11 quads, or onefourth, are not recovered for use in subsequent processes.

Other current fluidized-bed applications are not as energy-intensive, or often not as well established, as the major examples outlined above. These drying, mixing, chemically reacting, and heat exchanging applications for gas/solid or liquid/solid mixtures could significantly affect many industrial or energy conversion processes. How quickly applications could be developed depends in part on how much is known about fluidization in general, including its various modes, and on how that knowledge might apply in various situations. Developers are certainly handicapped by the current lack of fundamental understanding of the phenomenon. Despite fluidization's extensive application, designing fluidized beds is not currently possible without resorting to wholesale empiricism and trial-and-error methods-an expensive proposition.

Although fluidization has been the focus of a tremendous amount of applied research work in the past few decades, design and scale-up of commercial units from bench-scale data continually highlight shortcomings in understanding. In combustors, other reactors, and even dryers, laboratory-based correlations probably do not account for important physical phenomena that can become critical in actual operation. This problem is hardly unique to fluidization; for example, some of the difficulties with fluidized-bed combustors are similar to those in conventional coal combustion research. The situation is typical of difficult engineering problems: designers can create a device that works far more quickly than researchers can decide exactly how it works. The potential 
array of fluidization applications, however, provides the incentive for developing a better understanding of fluidization on a generic level.

\subsection{TURBULENCE IN FLUIDIZATION}

The difficulties with fluidization revolve around its fluid-mechanical complexity combined with the analytical dilemmas of chemical reactions (including combustion) and/or heat transfer. From the fluid mechanics standpoint, fluidization is a very complicated multiphase flow that must be broken down into zones or subprocesses to be studied adequately. Multiphase flows present very difficult experimentation and analysis problems, particularly when they involve turbulence. For example, a great deal of fundamental work on turbulent particle dispersion and diffusion remains to be done.

This section examines fluidized heds from a turbulence standpoint. Since even the usefulness of such a focus is debated, however, no attempt is made to completely delineate the interrelationships between turbulence and fluidization. In addition, turbulence is such a difficult problem that it is actively avoided by many researchers. Here, turbulence will be discussed simply in the fluid-mechanical sense of random, fluctuating flow excursions.

This section will primarily focus on the basic, bubbling fluidized hed. This is the "original" fluidized bed first developed for petroleum refining applications that has received the most research attention. In this flow regime, there is a definite interface between the gas-solid emulsion phase (which includes bubbles traveling upward through the emulsion) and the emulsion and the freeboard region above the bed into which the bubbles burst, spraying up particles. The two zones will be discussed separately. The implications of advanced bed designs such as fast (circulating) beds and pressurized beds are also discussed.

\subsubsection{In-Bed Turbulence}

A fluidized bed is a seething mass of particles. Each particle has a random path that, when averaged over time, forms eddies that depend (among other things) on fluidization velocity and the homogeneity and density of the particles in the bed. Measurements in the bed are exceedingly difficult to 
make; any probes significantly disturb the flow and become sources of bubbles. Non-intrusive laser measurements are not possible because of the opacity of the solids, except with two-dimensional experimental equipment that provides results that may be difficult to scale-up. Realistic measurement has been performed (which found the "averaged eddies" described above) with radioactive tracers at the Iniversity of Illinois; this work involved following a marked particle for many hours as it traveled in a bed. This is essentially the only good time-resolved measurement available, although a variety of local measurements have been made with laser probes.

Because of the difficulties in obtaining measurements, the role of random fluctuations (referred to here as turbulence) in fluidized beds has not been closely examined for engineering purposes. The University of Illinois work recorded fluctuating components, which are currently being analyzed. There is as yet no commonly accepted understanding of the nature of the turbulence, of its role in mixing or heat transfer within the bed, or of how it interacts with the bubbles that form in the bed and rise through it (giving the bubbling bed its name). It would seem likely that turbulence plays a considerable role in determining the transport properties of the bed, particularly in mixing and heat transfer. This makes in-bed turbulence a very important factor in determining bed performance.

\subsubsection{Freeboard Turbulence}

The freeboard is composed primarily of fluid, but also contains fastmoving particles spewed up by bubbles bursting at the hed surface. These particles may be carried along with a fluid flow (be entrained) and, if fast and light enough, may leave the reactor altogether (he elutriated). Although interactions between the freeboard and the bed are important, they are generally ignored in modeling efforts (Levy and Lockwood 1983) because little is known about them. The heterogeneous (two-phase) and fluid-phase reactions occurring in the freeboard are also significant (Delasa and Grace 1979).

Finally, elutriation and its effects on system efficiency can be very important indeed. Loss of carbon from fluidized-bed combustors is the primary cause of their carbon conversion inefficiency, even when expensive cyclone systems are used to remove carbon and other particulates (Arena, D'Amore, and 
Massimilla 1983). Carryover of catalysts requires expensive collection mechanisms in a variety of fluidized reactor applications. Elutriation correlations from a variety of experiments offer little universality (Wen and Chen 1982) and seldom aid in optimal design (Matsen 1979, George and Grace 1981). Freeboard flows must be more carefully characterized, since their highly fluctuating, turbulent nature makes simple approaches inaccurate.

It is important to note that high-velocity beds like the fast fluidized bed are similar in nature to the freeboard of a bubbling bed. Such beds are being rapidly developed into a viable option for the future, particularly for combustors. However, the highly turbulent flow and fine particles and extensive elutriation (requiring recirculation) make the fast fluidization regime exceedingly difficult to understand. Optical techniques developed for the freeboard of a bubbling bed may make it possible to probe this environment successfully. Very little data have been reported on mass transfer, heat transfer, or chemical reactions in such beds; all of these processes are greatly dependent on turbulence levels and characteristics. These data will be vital for designing fast-fluidized reactors.

The other advanced fluidized bed under consideration is the pressurized bed, although it is primarily being developed for large-scale coal combustion applications. Relatively few data are available on high-pressure fluidization, particularly in realistically sized units (Canada and McLaughlin 1978). Heat transfer is known to be enthanced, as would be expected from elementary theory. High pressure may not affect such basic bed characteristics as bed expansion and bed density, but operation is smoother, and therefore easier to control, than in atmospheric-pressure beds. The turbulent characteristics of such beds may partially explain this phenomenon. Since bed control is one of the most critical aspects in introducing this technology (and fluidized beds in general) to the market, the relationship between turbulence and bed control is an important issue. Usually, such control work begins after a design is more or less complete; better understanding of the relationship might aid in building more stable reactors. Finally, bed entrainment increases at high pressures, and could be a significant problem because of the costs and design 
problems of high-pressure cyclones. Again, turbulence levels and energy spectra and their role in this entrainment are vital pieces of design information.

\subsection{FLUIDIZATION RESEARCH}

Researchers in fluidization have not yet explored the concept of turbulence within a fluidized bed; indeed, the matter is often confused with the overall turbulent mode of the bed discussed at the beginning of this chapter. In addition, calculations of the flow past particles show that, except for rather large particles, the flow around a given particle is laminar or perhaps in transition. Thus it is difficult to focus on what is meant by turbulence in fluidization phenomena. The movements of individual particles within the bed, however, are highly random, as shown by the measurements at the University of Illinois. In addition, freeboard flows and fast fluidization are clearly turbulent. Because better understanding could significantly improve bed models, the study of these flows, and of bed fluid mechanics in general, is clearly important.

Fluid mechanicians do have a role in fluidization research, but they currently seem to limit their activities to carefully posed subset problems. These mechanicians and the more process application-oriented fluidized bed experts have not interacted particularly well. Substantial progress might be possible when realistic fluid mechanics become an integral part of complete fluidization models. Physical insights into the phenomena that permit expanded application of the results are vital.

It is important to consider, however, how fundamental such research should be to produce insights and understanding that reach beyond data correlations. Unfortunately the major difficulty with fluidization may be that the basic processes that combine to form a fluidized bed are very poorly understood. For example, entrainment of particles into flows is closely dependent on the turbulent energy spectrum of the flow, but there is little predictive capability in this area. Indeed, the whole subject of turbulent particle dispersion has significantly limited developing models of conventional coal combustion and other particulate flow systems. The mechanisms of turbulent heat transfer are not known in detail, even within a statistical description of the turbu?ence, 
and certainly are not known well enough to provide a framework for investigating the many heat transfer interactions in a fluidized bed. It appears that these and other very basic fields of inquiry need improved understanding, or at least some very good data, before modeling of fluidized beds becomes successful outside familiar ranges of application.

Fortunately, there is increasing attention among fluid mechanicians to these questions, and some basic work is underway. More applied work is also needed because fluidized beds are already in use, and data and improvements in understanding are required for evolutionary improvements and for sorting out how to apply the insights from this basic work. Because of improvements in instrumentation, research conducted specifically with fluidized beds does appear to be possible, although it might not have the broad applicability of the basic work on turbulent particle transport and heat transfer. Indeed, it will probably be quantitatively limited to the specific type of bed apparatus investigated.

There are some good examples of such work. Efforts to better understand mixing in the bed (and its relationship to turbulence) are an important generic area, for instance. In many applications, the mixing abilities and resultant uniform properties of fluidized beds are the primary reasons for their use. Mixing may be a key factor determining reaction rates, which are basic to the design of reactors. Aspects of mixing are important in drying applications as well; these applications are seldom optimized due to the lack of detailed knowledge about drying rates (Hopp et a1. 1981). The significance of work on fluidization mixing may be even greater in the future, because handling solids will probably become much more important, as lower-grade fuels and ores are increasingly utilized.

There are also measurement possibilities within fluidized bed freeboards. Detailed information about local gas and particle velocities is needed to gain sufficient insight into the anomalies of the entrainment and elutriation phenomena. Preliminary efforts (Levy and Lockwood 1983) have demonstrated a laser doppler anemometry (LDA) technique. Early results show that because of high gas velocities near the wall and the high turbulence caused by bubble eruptions, simple freeboard calculations based on time-averaged flow velocities 
and assumed uniformity between regions of the bed are highly inaccurate. Related work at Stanford (Kale and Eaton 1984) has further reinforced the value of detailed fluid mechanical investigations-and the need for basic understanding.

Other research possibilities might include further investigations within two-dimensional fluidized beds to examine particular points of difficulty in bed modeling (despite the limited applicability of the results). Because corrosion, fouling, and hot spots are significant concerns in the engineering of fluidized-bed reactors, detailed measurements and modeling of local flows are very important. With care, experiments to provide understanding of these flows might be constructed, just as detailed measurements of in-cylinder flows in engines are made in special, simplified research engines.

\subsection{DESIGN VIEW}

Current research measurement efforts have focused on steady (rather than fluctuating) flow components for several reasons. First, average quantities are usually needed for engineering purposes; thus time-resolved data are taken only if necessary. Second, even if such measurements are attempted, they are exceedingly difficult to obtain, even averaged data from fluidized heds are often found to be flawed. Third, turbulence data do not fit within any available theoretical framework. Numerous global models of fluidized beds have been developed by fluidized-bed experts with a good sense of how things should work, but using perhaps less than fully rigorous fluid mechanical analysis. These models comprise the current generation of design tools (Bywater 1978). To have an impact, research should pursue quantitative improvements of these models, or provide a generic hasis for improving current models or new apptications.

The preceding section emphasized research prospects related to turbulent flows in fluidized beds. Only the basic work has the potential to be broadly applicable and to provide a thorough understanding of flow details in fluidized beds. Because the fundamental processes examined in the basic work combine in very complex ways in given fluidization applications, applied work is also 
necessary. Further applied work may help develop sufficient understanding to improve current models, although perhaps not enough to completely revamp them.

\subsection{CONCLUSIONS FOR ECUT}

Applied fluidization research has definite limitations. The primary problem is the present lack of understanding of the fundamentals upon which the applied work should ideally be based. This problem has driven the move toward the correlation-based design approach currently in use: further applied work may only improve specific details of the models now used. In addition, such applied work may not be generic, and selecting one important application may strictly limit the impact and the rationale for any research. The most important applications, judging by magnitude of energy use, are fossil and biomass fuels conversion and petroleum processing, neither of which is a suitable topic for ECUT. A huge number of process applications exist, but as their implementation is based primarily on productivity concerns (although they may save energy as well) they would have to be carefully analyzed to evaluate their suitability. The remaining possibility focuses on one of the simpler advantages of a fluidized bed--its heat transfer capabilities.

Although the topic of fluidization is truly generic, with a tremendous (and increasing) range of applications, ECUT's participation should be limited to applications of fluidization to heat exchangers. In this way ECUT can be in position to utilize the basic research results that are necessary for proper understanding of fluidization, and can make important contributions because of both the strong need for such heat exchangers, and the increasing interest in the engineering community in doing so. In addition, because heat transfer is an element in some of the more complex applications of fluidization, such work might provide input to other programs as well. Ironically (given the focus of this report), turbulence may not be the most important factor to address within such a research program, although its contributing role should be of interest in other research problems. 


\subsection{CAVITATION}

Cavitation is generaliy defined as the formation of the vapor phase in a liquid through the reduction of its hydrodynamic pressure. Collapse of these vapor bubbles, often near a surface, creates tremendous shock loads and damage ranging from mild to catastrophic. Cavitation is a performance-limiting phenomenon that is to be avoided whenever possible. The complexity of cavitation inception, however, and its dependence on system-level fluid mechanical design, has not led to uniformly successful preventive measures. Cavitation (and cavitation damage) is still prevalent in U.S. industrial and power generation equipment. This chapter reviews the occurrence and the resulting significance of cavitation. Then the current knowledge of the role of turbulence in cavitation and prospects for research are presented. Finally, the design perspective and conclusions for ECUT are reviewed.

Cavitation can occur in many different ways, as its presence in a wide variety of fluid mechanical systems indicates. Engineering design can generally prevent the overall pressure in or around a given piece of equipment from dropping below fluid vapor pressure, so the basic conditions for inception are provided by local pressure variations in the fluid. A momentarily (and locally) low pressure, in combination with sufficient cavitation nuclei (small bubbles, dust, dirt, or surface sites) can cause cavitation bubbles to form. These bubbles then collapse explosively, causing tremendous shocks and damage to nearby surfaces.

From an engineering-design point of view, two basic questions about cavitation must be answered: Will it occur? And if it does, will the design still function acceptably? The second question arises partly because system or economic considerations may force operating the system in a cavitating regime, in addition to those occasions when such operation is not premeditated. Thus it is necessary to understand the effects of cavitation on normal operating loads. This report deals primarily with fluid mechanics and thus addresses the issues involved with the first question. 


\subsection{DEVICES IN WHICH CAVITATION OCCURS}

Cavitation is a design consideration for a wide variety of devices that handle liquids. It affects the performance of these devices in a number of ways--increased drag on ships, thrust limitations on propulsion systems, decreased power output and efficiency of water turbines, head and efficiency drops in pumps, etcetera. Cavitation can cause noise and vibration in valves, turbomachinery, and bearings, and also introduces the likelihood of erosion (0'Keefe 1983b). This erosion can occasionally induce disastrous failures very quickly; more often, it causes a gradual but significant performance decline. In special situations, cavitation can even be useful--ultrasonic cavitation is used to clean false teeth, for instance (Arndt 1981). In energy systems, however, cavitation is a widespread problem, and is now thought to be more complicated than was believed 20 years ago.

\subsection{SIGNIFICANCE OF CAVITATION}

The significance of cavitation (and thus of cavitation research) is very hard to quantify either in terms of energy loss or productivity. It is clear that the productivity losses are substantial, based on evidence from the power industry and from cavitation consultants. In many respects the situation is similar (though the occurrences are perhaps less diverse) to tribology, which focuses on friction, lubrication, and wear problems. PNL is currently studying tribological losses in industry for DOE; initial results indicate that energy losses are very difficult to quantify and that reducing these losses would probably be of far less interest to industry than the productivity gains obtainable from less frequent breakdowns or from having known wear rates. Cavitation damage is a tribological problem, so it is hardly surprising that the impacts of the two research areas would he similar. Unfortunately, this means that proper assessment of cavitation impacts would require a large-scale effort far beyond the scope of this report. Some factors relevant to energy conservation are briefly discussed, although no quantitative judgments are at tempted.

Cavitation has a considerable--and complex--relationship with energy conservation. Energy is wasted whenever optimum performance is not achieved; both 
unduty conservative designs and cavitating systems can waste energy. Conservatism is the prevailing mode in systems where scale-up is well understood, because the cold-water experiments used to make cavitation tests are generally conservative. Thus even flow devices in which non-scalable (e.g., turbulent) flows do not occur may be suboptimal because of ignorance of the relationships among working fluids. Whole installations may similarly be specified and operated in an unduly conservative manner.

From an industry perspective (based mostly on productivity), this is not really a great problem; the difficulty occurs when all of the extra conservatism is still rendered insufficient by factors such as turbulence and dissolved gases, and the cavitation degrades or fails the equipment. Because of the generic nature of cavitation phenomena, design and operating conservatisms and problems proliferate. Their quantification, even in the roughest manner, would require investigating many of the technical and institutional factors leading to cavitation damage. Without question, many compromises are made without sufficient knowledge of cavitation phenomena.

Installation designers and operators attempt to make conservative decisions with respect to cavitation, yet the phenomenon is still a considerable problem in industry. It occurs despite the fact that cavitation is well recognized as a design problem and is thus given considerable attention. In the case of pumps, for instance, the net positive suction head (NPSH) has received more attention than almost any other fluid handling topic (0'Keefe 1983a). NPSH is a hydraulics concept critical to cavitation that plays an active role in pump design and operation along with recirculation, flow rates, piping layouts and other factors.

If a pump's NPSH is set properly, the overall pressure of the fluid entering the pump should be enough to prevent cavitation from occurring inside it. However, the operating ranges specified for pumps may include areas where cavitation is already occurring, and cavitation caused by local flow phenomena can occur under part-load operation that cannot be arrested by normal control methods. In addition, pump specifications may be so vague (due to ignorance of the specifier) that details are left to the equipment supplier, who has no knowledge of the system in which the pump will be placed. Once a cavitating 
pump is in place, its cavitation may or may not be noticed. With a small pump in a closed loop, the noise will be evident; cavitation in big pumps or open loops will not be so obvious. If cavitation occurs in a pump, the consequences can be very severe. Whether or not performance is immediately reduced, the life of the pump will definitely be shortened (Tinney 1978). According to Tinney, cavitating pumps occur in large numbers in almost every industry, despite industry's reluctance to have that fact publicized. Clearly cavitation is in many ways a system design problem; it is also a problem at the more fundamental level of component design.

To answer the question, "When will cavitation occur?" while developing a given piece of fluid machinery, experimentation is essential. Because fluid machinery is often large and involves a variety of fluids, complete modeling must include factors related to scale-up and factors for extrapolation to fluids other than water, in which cavitation tests are generally conducted. Equipment cannot be tested for its full lifetime under all possible operating conditions, so the physics of cavitation inception must be sufficiently understood to model it properly. Lifetimes and maintenance schedules must at least be estimated. Infortunately, the question of operating conditions often takes on undue significance, since these conditions depend largely on the equipment to be used. As noted previously, equipment specification also has definite impact on system design, so design concerns on hoth equipment and system levels are closely related.

Research into cavitation can certainly contribute to component design, and perhaps to system design as well. Justifying such work is difficult, however, because of the uncertainty about cavitation's role and prevalence in industry. In addition, cavitation research is difficult and highly experimental, and is therefore expensive. The impacts of such work are essentially unknown, moreover, because of the diversity of cavitation in applications and its role as a constraint on both the design and operational phases of system performance. Most current work in the area is either funded by the military and conducted for specific applications (propellers, missiles and torpedoes for the Navy, and valves for the Air Force), or by pure-science sources such as the 
National Science Foundation (NSF). The NSF is presently funding work to quantify the influence of turbulence in cavitation, which may provide a starting point for more applications-oriented work. Neither group, however, has shown interest in determining the overall impact of their research.

The Electric Power Research Institute (EPRI) recently began an assessment of cavitation damage in the power industry (primarily in hydroelectric power installations). Results from Japan and the U.S. show that the damage can be significant; the impact has been broadly estimated at hundreds of millions of dollars each year. Only the catastrophic failures, such as the loss of a large water turbine or spillway, are evident. Much of the remaining damage is hidden in plant maintenance records, and as noted above, industry does not readily admit to having cavitation problems.

\subsection{HOW TURBULENCE IS INVOLVED}

As mentioned earlier, cavitation can occur in a system designed in accordance with standard procedures because of localized pressure variances. Perhaps the most striking conclusion of cavitation research in the past 20 years is that turbulence produces these variances and thus is a dominant factor in determining cavitation inception. Even localized turbulence caused by either the design or the operation of a fluid system can produce cavitation, despite contrary indications from the overall flow parameters. Viscous effects involving separating and reattaching boundary layers, effects of surface roughness, and turbulent shear flows all seem to have roles in cavitation inception, and closely involve turbulent phenomena. In addition, the effects of turbulent mass diffusion on the distribution of the nuclei (about which cavitation bubbles form) may be significant. These issues may become increasingly relevant, as various liquid systems such as cooling water loops or slurries witb higher speed and performance are put in place. These topics are discussed in more detail in the following section; most of the material included here is derived from a recent review paper on the fluid mechanical aspects of cavitation (Arndt 1981). 


\subsubsection{Viscous Effects}

Boundary layer development, transition, and separation can have a marked effect on cavitation. Turbulence is involved in flow separation and transition. Cavitation during separation generally occurs in the separated shear layer as a result of low-pressure peaks in the transition or turbulent sections of the separation region. Combined with microscopic freestream nuclei as they are swept by, these peaks are sufficient to cause cavitation (Katz 1984). There are indications that specific vortices within the turbulent separation region may be important, at least in two-dimensional flows (Katz 1984, Katz and 0 'Hern 1983). These vortices, and in particular their strength and dependence on flow conditions, are not well understood, and are primarily the subject of fundamental research. Although separated flows occur with considerable frequency in high-speed pumps, in valves, in piping systems, and even in heat exchangers, too little is known about the vortices in laboratory situations, much less in application, to permit any immediate attempt to develop remedies.

\subsubsection{Surface Roughness}

The degree of surface finish can be a controlling factor in the cavitation inception process. Strictly speaking, it is simply another viscous effect. Isolated asperities have little influence on boundary layer development, but can cause considerable local cavitation. Uniform roughness increases turbulence intensity, and cavitation then occurs in the cores of large eddies in the boundary layer, much as they might occur (although less intensely) in a turbulent boundary layer near a smooth wall. Increases in cavitation for equivalent protuberances are much greater for isolated lumps than for uniform roughness, but the latter shows a sharp rise heyond a particular level of roughness (Arndt, et al. 1979). The implications of these findings for service life are enormous, e.g., if cavitation from some other source has damaged the surface slightly. Indeed, very few liquid-flow systems are smooth in the first place.

\subsubsection{Turbulent Shear Flows}

Turbulence is a primary factor in cavitation in free turhulent shear flows, which may occur in large pumps and other large-scale flow systems. Laboratory experiments currently do not provide reasonable estimates of when 
the flow in a new equipment prototype will cavitate. This problem is perhaps even more critical than the problems of flow over surfaces discussed above, because there is presently no definable upper limit on the cavitation index for free shear flows.

The problem has two aspects: the diffusion of nuclei into the minimumpressure region, and the intensity and spectrum of turbulent pressure fluctuations. Both the size distribution of the nuclei and the turbulence spectrum contribute to determining critical pressure in the inception region. The unsteady pressure field is the major contributor to the problem, since spatial variations in time-mean pressure fields due to turbulence are normally minor. Temporal fluctuations are thus at the heart of the cavitation problem. Scaling laws must be found for amplitudes and spectral characteristics of the pressure field. For cavitation to occur, local pressure drops must have both a relatively high statistical occurrence and sufficient duration to produce bubble growth. This is basic to cavitation in the boundary layer as well.

\subsubsection{Dissolved Gas Effects}

The influence of free and dissolved gases on cavitation inception is based on their effects on nuclei distribution and population. Dissolved gas can also influence the hydrodynamic loads produced in cavitating flows, through its effects on the acoustic properties of the fluid. Although these considerations are not directly discussed in this report, the turbulent dispersion of gas is a factor in both cavitation inception and cavitation damage. Preliminary results indicate that turbulence speeds the dispersion of gas considerably, but the significance of this result for cavitation is not known (Brennen 1969).

\subsection{RESEARCH}

Significant advances in knowledge about cavitation may be possible, in part because of advances in instrumentation for time-resolved flow visualization and measurement. The controlling variable in cavitation, however, is pressure, which cannot he directly measured with these methods. As a result, the experimental determination of turbulent pressure fields is very difficult, although progress has been made. Theoretical determination is still in its infancy, and usually involves extension of older concepts (Batchelor 1953) to 
homogeneous, isotropic, turbulent flows with and without shear. When compared with experimental data, these efforts have shown that pressure fluctuations in a shear flow are of higher intensity than those in isotropic turbulence.

Spectrat characteristics of pressure fields can be inferred theoretically, with relatively high accuracy. Unfortunately, this work does not clarify the important role that coherent structures play in determining at least the larger-scale pressure fluctuations. Cavitation in highty turbulent jets, for instance, occurs in rings. In addition, most experimental and theoretical information on turbulent pressure fields is in the Eulerian (fixed) frame of reference. Cavitation inception requires pressure information from a Lagrangian (particle-following) viewpoint.

In sumary, the available data on cavitation inception in turbulent flows are difficult to relate to the information on turbulent pressure fields in both boundary layers and free shear flows. Theoretical approaches cannot handle some of the flow structures that appear to be important, and only 1 imited data have been collected. Indeed, the observed cavitation inception is not related to observed turbulence parameters in most situations. Cavitation in turbulent shear flows, in particular, is the result of a complex interaction between an unsteady pressure field and distribution of free-stream nuclei. What little data are available indicate that inception is induced by pressure excursions (these can be less than one-tenth the root mean square pressure) and that further attention must be given to details of the turbulent pressure field. In time, consideration will have to be given to cavitation cases in which mass diffusion and perhaps heat transfer are equally important as the flowfield. The question of how flow patterns vary with changes in thermodynamic properties, for instance, is very significant, and can occur with regularity in many applications. At present, researchers can only guess about how these effects influence cavitation inception.

Two general observations, however, can presently be made. First, as the scale of the flow increases, cavitation nuclei become relatively more responsive to a wider range of pressure fluctuations. Also, it appears that large pressure deviations are more probable at a higher Reynolds number, which explains the observed increase of cavitation probability with physical scale. 
Far more remains to be learned, however. What is important, in making research decisions for a problem for which so much fundamental work is needed, is whether research results will have a strong role in producing better designs.

\subsection{DESIGN VIEW}

Basic cavitation scaling laws and standard design methodologies use the cavitation index, a simple relationship involving fluid velocity, density, pressure, and vapor pressure. The suitability of this index depends on the assumptions of an inviscid fluid and the occurrence of cavitation when the pressure in the flowfield equals the vapor pressure at the bulk temperature. If these assumptions are granted, the cavitation index becomes the primary scaling factor for cavitation inception and all other hydrodynamic parameters involving cavitating flow. This simple scaling has severe limitations, however. One is that the assumptions do not always hold--they do not take into account viscosity, for instance--and thus cannot account for the turbulencerelated loca? flow phenomena discussed above, which have been found to affect cavitation inception.

A second concern is that the index does not embody enough knowledge about cavitation to permit simple extrapolation of the experimental results used to set operating limits for particular pieces of equipment. Most cavitation experiments can take laboratory data covering only a narrow range of independent variables. Thus, little information is available for judging the correlation between a laboratory version of a particular piece of flow machinery and the full-scale version.

Thus, from the design point of view, better formulations of scaling laws, which will certainly require an effective understanding of the details of cavitation inception (including the role of turbulence), are very important. Such formulations will not ensure cavitation-free operation, however; system-level design must also be properly executed. In some ways this concern is more critical than the research, as it is necessary to translate the research into positive results. The implications of this point for ECIIT will be discussed in the following section. 
Conservation-oriented research in cavitation would apply a new focus to efforts in that field. Unlike past efforts dominated by propulsion or civil engineers, this focus would be on the problems occurring in industrial installations. These problems can be traced back to either improper specification or operation of the installation or to fluid mechanical design based on insufficient knowledge. In the latter case, the knowledge to be gained often relates to turbulence-cavitation interactions. Through ECUT, DOE could help develop the basic knowledge necessary to avoid such problems. Additional benefits could also result from such a program -. knowledge on flows in certain industrial systems that could be useful in research aimed at drag reduction, and contacts with the manufacturers of pumps and valves, for instance. These devices, it is important to note, are an essential part of the technology base for energy conversion systems. The difficulties in implementing nuclear power, for example, are in part traceable to insufficient understanding of valve design.

The research needs for cavitation, however, appear to be very fundamental. It is not clear which flow effects must be included in formulating predictive models or design tools, since there is little correlation between currently measurable parameters and cavitation incidence. Recause of the additional complications of integrating eventual results into system design procedures, ECUT should not presently hecome involved in this area. As the more fundamental work progresses, the area should be reevaluated, and perhaps sone work on research impacts completed.

At present cavitation serves as an ideal example of the role of fluid mechanical problems in industry, involving both the very basic research indicative of the as-yet-unresolved nature of much of fluid mechanics and the systemlevel design problems that inhibit the operation of current fluid mechanical devices in so many applications. Finally, like so many industrial problem areas, the driving force for improvements results from the broad goal of improved productivity, rather than the narrower objective of energy conservation. 


\section{REFERENCES}

Abarcar, R. B., G. J. Hane, D. R. Johnson. 1984. ECUT Energy Data Reference Series: High-Temperature Materials for Advanced Heat Engines. PNL-5193, Pacific Northwest Laboratory, Richland, Washington.

Arena, U. M., D'Amore and L. Massimi11a. 1983. "Carbon Attrition During the Fluidized Combustion of Coal." AICHE Journal 29(1):40-49.

Arndt, R. E. A. 1981. "Cavitation in Fluid Machinery and Hydraulic Structures." Annual Review of Fluid Mechanics 13:273-328.

Arndt, R. E. A., et al. 1979. "The Influence of Surface Irregularities on Cavitation Performance." Journal of Ship Research 23:157-170.

Batchelor, G. K. 1953. The Theory of Homogeneous Turbulence. Cambridge University Press, Cambridge, England.

Blair, M. F. 1983. "Influence of Free-Stream Turbulence on Turbulent Boundary - Layer Heat Transfer," Parts I and II. ASME Journal of Heat Transfer 105(1):33-47.

Bodine, J. F. and M. Vitullo. 1980. Oak Ridge Associated Universities (ORAU): Industrial Energy Use Data Book. ORAU, Oak Ridge, Tennessee.

Bradshaw, P. and P. Simonich. 1978. "Effect of Free-Stream Turbulence on Heat Transfer Through a Turbulent Boundary Layer." Journal of Heat Transfer $100(4): 671-677$.

Brennen, C. 1969. "The Dynamic Balances of Dissolved Air and Heat in Natural Cavity Flows." Journal of Fluid Mechanics 37:115-127.

Canada, G. S. and M. H. MCLaughlin. 1978. "Large Particle Fluidization and Heat Transfer at High Pressures." In Fluidization Application to Coal Conversion Processes. AICHE Symposium Series \#176, Volume 4. American Institute of Chemicat Engineers (AICHE), New York.

Bywater, R. J. 1978. "Fluidized Bed Catalytic Reactor According to a Statistical Fluid Mechanics Model." In Fluidization Application to Coal Conversion Processes. AICHE Symposium Series, \#176, Volume 4. American Institute of Chemical Engi neers (AICHE), New York.

Cantwe11, B. J. 1981. "Organized Motion in Turbulent Flow." Annual Review of Fluid Mechanics 13:457-515.

De Lasa, H. and J. R. Grace. 1979. "The Influence of the Freeboard Region in a Fluidized Bed Catalytic Cracking Regenerator." AICHE Journal 25(6):984991. 
Dunne, J. 1984. "Detroit's Big Switch to Turbo Power." Popular Science $224(4): 78-81$.

George, S. E., and J.R. Grace. 1981. "Entrainment of Particle from a Pilot Scale Fluidized Bed." Canadian Journal of Chemical Engineering 59:279.

Hane, G. J. and D. R. Johnson. 1984. ECUT Energy Data Reference Series: 0tto Cycle Engines in Transportation. PNL-5191, Pacific Northwest Laboratory, Richland, Washington.

Hopp, W. J., et al. 1981. An Overview of Energy Conservation Research Opportunities. PNL-3944, Pacific Northwest Laboratory, Richland, Washington.

Hutchinson, R. A. and H. J. Bomelburg. 1984. Capabilities of Laser Diagnostics for Combustion and Flowfields. PNL-5280, Pacific Northwest Laboratory, Richtand, Washington.

Hutchinson, R. A. 1985. Applications of Laser Diagnostics in Energy Conservation Research. PNL-5281, Pacific Northwest Laboratory, Richland, Washington.

Imhoff, C. H., A. Liberman, and W. B. Ashton. 1982. U.S. Energy Conversion and Use Characteristics. PNL-4075, Pacific Northwest Laboratory, Richland, Washington.

Kale, S. R., and J. K. Eaton. 1984. "An Experimental Investigation on the Effect of Diffusers on Elutriation Rates from Fluidized Beds." In Gas-Solid Flows, ed. J. T. Jurewicz, PP. 107-114. American Society of Mechanical Engineers (ASME), New York.

Katz, J. and T. J. O*Hern. 1983. Cavitation in Large Scale Shear Flows. ASME Publication 83-FE-33, American Society of Mechanical Engineers (ASME), New York.

Katz, J. 1984. "Cavitation Phenomena Within Regions of Flow Separation." Journal of Fluid Mechanics. 140:397-436.

Laufer, J. 1983. "Deterministic and Stochastic Aspects of Turbulence." Journal of Applied Mechanics. 50:1079-1085.

Levy, Y., and F. C. Lockwood. 1983. "Laser Doppler Measurements of Flow in Freeboard of a Fluidized Bed." AICHE Journal 29(6):889-895.

Lumley, J. L. 1983. "Turbulence Modling." Journal of Applied Mechanics $50: 1097-1103$.

Matsen, J. M. 1979. "Entrainment Research: Achievements and Opportunities." In Proceedings of the NSF Workshop on Fluidization and Fluid-Particle Systems. ed. H. Littman, p. 452 . National Science Foundation, Washington, D.C. 
O'Keefe, W. 1983a. "How to Make Problem Pumping Give Better NPSH Performance." Power. 127(8):25-32.

O'Keefe, W. 1983b. "Valves - A Special Report." Power. 127(2):82.

Rogallo, R. S., and P. Moin. 1984. "Numerical Simulation of Turbulent Flows." Ann. Rev. Fluid Mechanics. 16:99-137.

Schroppe, J. T., and R. L. Gamble. 1982. "Fluid 8ed Units Gain Acceptance and Come of Age." Paper presented at the American Power Conference, April 125 , 1982, Chicago, Illinois.

Shercliff, J. A. 1981. "Reflections of a New Editor." Journal of Fluid Mechanics. 106:349-356.

Siman-Tov, M., and J. E. Jones. 1980. "Technology Assessment for an Atmospheric Fluidized-8ed Combustion Oemonstration Plant." Paper presented at the 6th International Conference on Fluidized Bed Combustion, April 9-11, 1980, Atlanta, Georgia. Also available as Conf. 800428 from National

Technical Information Service, Springfield, Virginia.

Tinney, W. S. 1978. "How to Obtain Trouble-Free Performance from Centrifugal Pumps." Chemical Engineering. June 1978.

Wen, C. Y., and L. H. Chen. 1982. "Fluidized 8ed Freeboard Phenomena: Entrainment and Elutriation." AICHE Journal. 28(1):117-128.

Witze, P. 0. and T. M. Dyer. 1984. "Laser Measurement Techniques Applied to Turbulent Combustion in Piston Engines." Presented at the ASME 105th winter Annual Meeting, New Orleans, Loui siana. SAND84-8759, Sandia National Laboratories, Albuquerque, New Mexico.

Yerushalmi, J., and A. M. Squires. 1977. "The Phenomenon of Fast Fluidization." In Fluidization Theories and Applications, ed. J. S. Halow, pp. 44-50. American Institute of Chemical Engineers, New York.

Yerushalmi, J., N. T. Cankuro, D. Geldart, and 8. Liss. 1978. "Flow Regimes in Vertical Gas-Solid Contact Systems." In Fluidization: Application to Coal Conversion Processes. AICHE Symposium Series, \#176, Volume 4. American Institute of Chemical Engineers (AICHE), New York.

Zabrodsky, S. S. 1966. Hydrodynamics and Heat Transfer in Fluidized 8eds. MIT Press, Cambridge, Massachusetts. 

No. of

Copies

DFFSITE

20 M. Gunn

U.S. Department of Energy

Energy Conversion and

lutilization Division

1G-080 Forrestal Ruilding

Washington, D.C. 20585

3. Brogan

U.S. Department of Energy

Office of Energy Systems

Research

Washington, П.C. $2 \Pi 585$

J. J. Eberhardt

CE-14?

II.S. Department of Energy

$10 n 0$ Independence Avenue

Washington, D.C. 20585

T. Levinson

CE-14?

U.S. Department of Energy

1000 Independence Avenue

Washington, D.C. 20585

30 DOE Technical Information Center

R. Abarcar

Energetics, Inc.

9210 Route 108

Columhia, Mn 21045

J. A. Carpenter

Oak Ridge National Lahoratory

P.0. Rox $x$

Building 4508 North Room 263

Oak Ridge, TN 37830

M. Bernard

Argonne National Lahoratory

Building 362-2B

Argonne, IL 60439
No. of

Copies

J. Kane

Basic Energy Sciences

U.S. Department of Energy

$E R-10$

Washington, D.C. 20545

K. G. Kreider

U.S. Department of Commerce

National Rureau of Standards

Physics $\mathrm{B}-250$

Washington, D.C. 20234

W. Thielbar

U.S. Department of Energy

Idaho Operations office

550 Second Street

Idaho Falls, ID 83401

T. M. Dyer

Sandia Laboratories

P.0. Box 969

Livermore, CA 94550

M. Kaminsky

Argonne National Laboratory

9700 South Cass Avenue

Argonne, IL 60439

R. E. A. Arndt

St. Anthony Falls Hydraulic Lab

University of Minnesota

Minneapolis, MN 55455

P. 0. Witze

Sandia Laboratories

P.0. Box 969

Livermore, CA 94550

M. M. Chen

144 Mechanical Engineering

मातो.

$1206 \mathrm{~W}$. Green St.

University of Illinois

Urbana, IL 61801 
No. of

Cooies

A. Rejan

Mechanical Engineering Dept.

Dulze University

Durham, NC

Dr. J. Grace

Dept. of Chemical Engineering Iniversity of British Columbia 2216 Main Mal1

Vancouver, Canada V6TIW5

Dr. Win Aung

Heat Transfer Program

Nationa 1 Science Foundation

$1800 \mathrm{G}$. Street

Washingt on, n.C.
No. of

Copies

ONSITE

DOE Richland Operations

H. E. Ransom/n. R. Segna

43 Pacific Northwest Laboratory

W. R. Ashton

J. M. Bates

D. L. Brenchley

W. C. Cliff

R. A. Hutchinson (30)

D. C. Kuick

J. R. Skarda

Publishing Coordination MH (2)

Technical Information (5) 